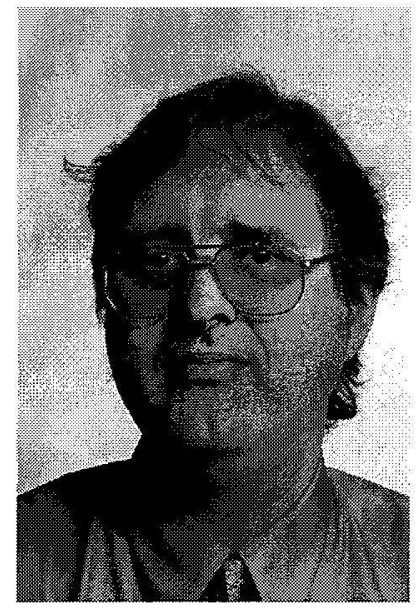

\title{
FUNCTIONAL LABOUR MARKETS REVEALED BY TRAVEL TO WORK DATA 1991 AND 2001
}

\author{
James Newell ${ }^{*}$ and Martin Perry ${ }^{* * 1}$ \\ ${ }^{*}$ Monitoring and Evaluation Research \\ Associates, PO Box 2445, Wellington \\ and \\ ** Labour Market Policy Group, \\ Department of Labour
}

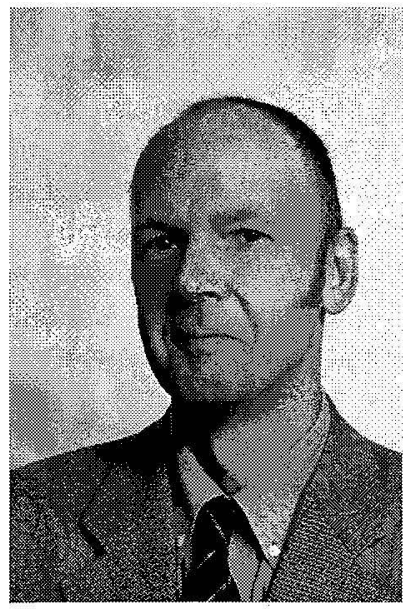

\begin{abstract}
Regional labour market analysis is ideally based on functional rather than administrative areas. Travel-to-work data obtained from the 1991 and 2001 Census are used to define a set of functional labour markets for New Zealand. Considerable stability is found in the boundaries of the identified labour markets 1991 and 2001 although with a reduction in the number of areas from 140 to 106. The overall stability in the identified areas suggests that they provide a robust basis for regional analysis. The reduction in the number of areas is explained in part by data deficiencies associated with the 2001 Census and in some instances by changes in commuting patterns.
\end{abstract}

\section{Introduction}

From a geographical perspective, labour markets can be delineated by the distance employees travel to work (Ball, 1980; Coombes and Openshaw, 1986). From any centre of population, journey-to-work time and cost constrain the spatial area over which residents commute to work. Travel to work patterns may thus be used to identify labour market catchment areas. It has long been recognised that such catchments can provide a more meaningful basis for monitoring local employment change than the use of administrative boundaries. For example, the interpretation of migration data based on administrative boundaries is restricted by the uncertainty over how much of this movement involves a change of employment (Maré and Choy, 2001). In comparison, migration across travel to work catchments is less ambiguously related to changes in employment (Green, 1994).

The New Zealand Census collects information about place of residence and work to enable the delineation of labour catchments. Even so there is no tradition of using functional labour market areas as a basis for monitoring sub-national employment change. A system of travel to work areas based on 1991 Census data represents the only published use of Census data for defining local labour markets (Newell and Papps, 2001). Its analysis separated New Zealand into 140 functional labour markets including many that straddled local authority boundaries. This paper uses the same analytical framework to prepare a comparative set of labour market catchments based on 2001 Census data. The comparison includes evaluation of the stability of the 1991 catchment areas and the generation of new travel to work catchments.

A reduction in the number of catchments is found to have taken place from 1991 to 2001, mainly through the amalgamation of areas. A further part of the reduction is explained by differences in data coding between the 1991 to 2001 Census rather than changes in travel to work. Overall, therefore, considerable stability is found in the 1991 labour market catchment areas. High levels of selfcontainment are maintained for sub-groups identified by gender, ethnicity, hours worked, income, occupation and age. The consistency among labour market groups further underlines the potential usefulness of the catchment areas for studying regional employment change.

The main purpose of this paper is to demonstrate the continuity between local labour market areas based on 1991 and 2001 data. Prior to presenting this analysis further justification for the use of travel to work patterns is provided followed by a brief outline of the method adopted for defining labour market catchments.

The views represented in this paper are the author's own and should not be taken to represent the views of the Department of Labour 


\section{Travel to work areas}

The case for defining local labour markets according to travel to work patterns needs to substantiate the deficiency of administrative boundaries and demonstrate the robustness of travel to work areas.

The hierarchy of administrative areas provides the most frequently used sub-national boundaries for labour market analysis. This is to be expected from the wide recognition of administrative boundaries and relationship with public agency responsibilities. The attempt to propagate a further set of boundaries requires evidence of a clear need. Four issues contribute to this case.

First, few if any set of areas in a national administrative hierarchy provide fully comparable units for spatial analysis (Coombes, 2001). For example, the four main New Zealand urban regions as defined by regional council boundaries vary in total population from 1.16 million (Auckland) to 181,540 (Otago). The Auckland and Wellington regions each encompass four cities with separate administrative jurisdictions. In contrast, the two South Island regions are distinguished by their geographical extensiveness. Going down the urban hierarchy identifies a group of 15 cities with a larger population range than regional councils and much variation in their proximity to other population centres. The absence of comparably defined areas is a constraint when seeking to analyse urbanisation processes. Many patterns and processes are shaped by the distribution of urban and rural areas. Consequently, to provide meaningful and comparable units for analysis, a set of areas need to be defined in relation to these settlement features. This problem is amplified further when seeking to make cross-national comparisons. The comparatively small population size of New Zealand regions makes it difficult, for example, to interpret the relative importance of regional labour market adjustments that occur in response to employment shocks (Choy et al., 2002).

Second, the use of consistently and appropriately defined area boundaries is especially important for comparing local unemployment rates. Unemployment reflects a shortfall in labour demand relative to labour supply. The respective location of workers and employment opportunities is, therefore, a critical determinant of local unemployment rates. Low-income workers are both the most likely to be unemployed and to have the most restricted residential options among employment groups. As a result, the extent to which a particular administrative boundary embraces or excludes a low-income housing area potentially has a significant impact upon reported unemployment rates. In this context it is particularly important to ensure unemployment rates are expressed for a comparable set of areas. A further extension of this arises where welfare assistance depends on the 'job testing' of applicants. Claims about the inability to find suitable employment require evaluation against the geographical area that it is reasonable to expect employment search to be confined to.
Third, the use of travel to work catchments minimises the opportunity to selectively present spatial statistics. Much employment policy intervention seeks to ensure that workforce characteristics reflect the attributes of the population from which the workforce is potentially drawn. This is typically motivated by a wish to raise the employment of specific social groups such disabled persons, ethnic minorities, new migrants and long-term unemployed. When monitoring progress against these goals for sub-national populations, results can be sensitive to the area boundaries that are used. Ethnic groups, for example, tend to cluster in particular residential areas. Judging their representation in a locality's workforce depends on the distribution of these clusters relative to the area boundaries defining the locality. Where administrative boundaries are the only option for assessing representativeness, judgements may be affected by the administrative boundary selected. It is preferable that the evaluation is based on the most appropriate area. In this context, appropriateness means the local labour market area that best represents the workforce relative to places of employment. Travel to work areas provide this representation on the basis of an objectively defined area.

Four, promulgating travel to work catchments can establish a standard for spatial data analysis in a context where the dependence of data users on administrative boundaries is reducing (Coombes, 2001). GIS-based software is increasing the ease of aggregating data to non-standard areas and encouraging data users to demand greater flexibility in the release of official statistics. This may be a challenge to statistical agencies that in the past have determined the appropriate areas for which data should be released. This decision has usually involved selecting the lowest tier of the administrative hierarchy providing sufficient statistical reliability and confidentiality protection. Responding to the expectations of increased data flexibility gives a risk of statistics being misused and of reduced comparability between individual investigations. Identifying standards with respect to the types of area appropriate for analysis is a way statistical agencies can respond to user expectations while maintaining a role in controlling the use of official statistics.

Of course, any system of boundaries is likely to have some limitations. A potential shortcoming of travel to work catchments is the lack of continuity between boundaries over time. Reform of administrative systems causing a change in boundaries potentially occurs less frequently than changes in journey to work patterns. This arises partly because of the impact of investment in housing and transport infrastructure and the changing cost of personal mobility. As well, travel to work areas are sensitive to the economic conditions that exist when input data are collected. Job search may be expected to occur over a wider geographical area in times of comparative labour surplus than in times of comparative labour shortage. At times of low labour demand, depending on the distribution of unemployment among 
occupational groups, the catchment may be distorted by not including the potential journeys of those out of work.

Related to the potential instability generated by unemployment, the acceptability of generating boundaries on the average behaviour of the working population is a further potential weakness. Boundaries may vary, for example, according to whether male or female journey to work is measured. Use of travel to work patterns requires evidence of the comparative stability in the areas and high self-containment between social groups. Prior to exploring how well the New Zealand boundaries perform against these criteria further explanation of the method by which they are generated is provided.

\section{Defining travel to work areas}

A well-defined local labour market area should possess two characteristics. First, a high degree of self containment, as reflected in minimal travel to work across the generated boundaries. Second, a high degree of intraarea movement such that the area is internally integrated (Goodman, 1970; Ball, 1980; Coombes and Openshaw, 1982). To achieve these attributes, the method developed by Coombes et al. (1986) was adopted for the analysis based on 1991 data (Newell and Papps, 2001) and for the present study. Full description of the method can be found in the earlier study, here a summary of the key aspects of the approach are described with discussion of the issues arising in seeking comparability between the 1991 and 2001 areas.

The approach proscribes a minimum self-containment and population size for each local labour market of 70 percent and 2,000 workers respectively. It also establishes 'target' values of 75 percent and 17,700. To be designated a separate area, in the first instance at least one of the target values needs to be attained. If neither target value is obtained, a threshold value representing a 'trade-off between the minimum self-containment and size factors has to be satisfied. The minimum and target population values are below those in the Coombes methodology to reflect New Zealand's comparative small population and low population density and differences in the scope of the data utilised.

A computerised algorithm processes the source data in four stages.

1. Identify every highly self-contained Census unit area (area units in the case of the 1991 analysis and a combination of area units and mesh blocks for the 2001 analysis) and every area unit with a high rate of in-commuting. Each of these areas is identified as a potential 'focus' of a local labour market.

2. Foci that have high levels of commuting between them are linked together.
3. Incrementally assign all the non-foci area units to the foci they are most strongly attached to. This process commences with the areas that have the strongest commuting links to the foci and ends with the area with the weakest links to other areas.

4. Rank the 'proto travel to work catchments' according to the size and self containment criteria. Starting with those proto catchments furthest away from meeting those criteria, constituent Census units are reallocated to the emerging labour market area that has satisfied the size criteria. This process continues until all catchments make the set criteria.

Applied to New Zealand, the modified Coombes algorithm produces labour markets with comparatively high levels of self-containment (typically at least 85 percent) and small workforces (9-10,000 employed persons). The number of separate labour markets identified is more sensitive to the self-containment criteria than the population criteria (Newell and Papps, 2001). Thus even though most areas exceed the minimum self-containment level of 70 percent, modifying this value produces significant variation in the number of local labour markets.

\section{Issues in compiling 2001 catchment areas}

Replication of the 1991 analysis using 2001 Census data required some additional analytical steps because of differences in the proportion of Census returns that provide both a specific residential and workplace address. This has the effect of reducing the robustness of the 2001 boundaries compared with 1991, although as the majority of areas remained unchanged the analysis is felt to retain its integrity.

Comparability of the 1991 and 2001 analysis requires that the same spatial reference frame is used and that the data variables (usual residence, workplace location and labour market attributes) are coded in the same way.

Area units were used in the 1991 analysis. Given some adjustment in area unit boundaries between 1991 and 2001 , the more recent analysis required incorporation of meshblock level data to enable a comparable set of base areas to be identified. Data on residence is coded to the meshblock level in each census for all respondents. In contrast, only a proportion of respondents identifying themselves as employed provided sufficient information to code their workplace location to a meshblock (although typically there is sufficient information to code them to a larger area unit). A problem arises where the gap involves respondents residing in meshblocks that need to be reallocated to a different area unit. Workplace records coded to 2001 area units and not to the meshblock level could not be unambiguously assigned to 1991 area units. Those observations had to be rejected from the initial dataset. 
The end result is that a proportion of those identified as employed are able to be coded for both residence and workplace in 1991 and 2001. The initial result of this rebasing process for the 1991 dataset resulted in about 92 percent of those identifying themselves as employed in 1991 coded to area unit but only about 84 percent of those identifying themselves as employed coded to 1991 workplace area unit for 2001 .

An adjustment was required to avoid the 2001 analysis being based on a smaller workforce population than the 1991 analysis. To achieve this comparability, 2001 data were scaled to the same level of completeness as the 1991 data assuming that missing workplace addresses exhibited the same distribution of locations as the coded addresses. This procedure resulted in a 36 percent reduction in the number of local labour markets identified in 2001 compared with 1991 (from 140 to 90).

A further difference between the 1991 and 2001 Census data is the proportion of long distance commutes such as a journey to work from Tauranga to Auckland. Such commutes were more frequent in 2001 and 1991 and present a problem for the analysis. The idea of a travel to work area is to capture the area within which the working population habitually seeks employment and where local employers recruit most of their labour. In this sense, idiosyncratic travel patterns arising through unusual circumstances or existing as a temporary transition to relocation might be ignored. It is also possible that respondents in 'field' roles may identify a head office work location rather than the area they work within. On the other hand, an increase in long-distance commuting on a weekly if not daily basis may be an aspect of changing work patterns. For example, flexible employment practices such as extended shift hours to facilitate shorter working weeks or a combination of home-based and workplace activity made possible through information technology. Dual income households, contract-based employment and high incomes also make an increase in long distance commuting possible.

Table 1 Proportion of journeys to work eligible for omission due to distance travelled

\begin{tabular}{|lcc|}
\hline & Proportion of trips omitted due to long distance \\
Region of trip destination & 1991 & 2001 \\
\hline Northland & 0.5 & 2.04 \\
Auckland & 0.29 & 0.88 \\
Waikato & 0.32 & 0.92 \\
Bay Of Plenty & 0.74 & 2.9 \\
Gisborne & 0.63 & 2.75 \\
Hawke's Bay & 0.5 & 2.38 \\
Taranaki & 0.68 & 1.68 \\
Manawatu-Wanganui & 0.29 & 1.61 \\
Wellington & 0.37 & 1.88 \\
Marlborough & 0.67 & 5.78 \\
Nelson & 1.03 & 4.43 \\
Tasman & 0.33 & 3.42 \\
West Coast & 0.72 & 3.62 \\
Canterbury & 0.31 & 1.23 \\
Otago & 0.35 & 1.7 \\
Southland & 0.21 & 2.16 \\
\hline All regions & 0.41 & 1.59 \\
\hline
\end{tabular}

Although the proportion of these problematic trips is small they have a large influence on some catchment boundaries. For this reason, a screen was devised made up of region-to-region travel to work combinations that were considered usual on the basis of geography and 1991 travel to work data. Those observations were then filtered from the 2001 travel to work matrix and the data scaled back to the same level of capture as 1991 data. This step conserved 18 labour markets.

The final number of local labour market catchments identified for 2001 was 108 versus the 140 in 1991. The long distance observations discarded represented 1.6 percent of all trips in 2001 . By contrast, only 0.4 percent of 1991 travel to work observations would have been screened under this protocol. Marlborough is the most affected region with 5.8 percent of observations screened out for 2001 compared to only 0.7 percent being eligible for such screening in 1991.

\section{1 labour market catchments on 1991 area unit boundaries}

A principal purpose of the present study is to examine how well preserved the 1991 boundaries are in 2001. As noted, for comparability, this requires that the 2001 data are applied to 1991 area boundaries. A separate analysis was also envisaged based on 2001 meshblock data. In 
practice it was decided that because of the comparatively high proportion of 2001 responses without a meshblock workplace address it was not feasible to construct a new set of areas from this micro level. Instead the 2001 areas were compiled using area unit level data with results showing little difference from the areas based on 1991 area units.

Bearing in mind the tendency for area unit boundaries to be maintained between Censuses, the discussion of findings focuses on the boundaries generated from 1991 area units. As noted above, this shows a fall in the number of local labour markets from 140 to 108 . Before reviewing the change, salient features of the 1991 boundaries to be noted are as follows (for further details see Newell and Papps, 2001).

- The labour markets vary in employment size from 273,603 (Central Auckland) to 36 areas with fewer than 1,000 employees.

- The geographical area of labour catchments varied between 6 square kilometres (Waiouru) and over 11,200 square kilometres (Te Anau).

- The main urban centres have extensive labour markets. The Auckland metropolitan region, for example, was divided into two catchments split around Onehunga-Panmure south of the central city. The Christchurch labour market stretches inland to Arthur's Pass, but excluding part of the Banks Peninsula.

- For the most part, labour market areas are geographically contiguous. Exceptions partly reflect physical geography, such as Featherston's inclusion in the Wellington labour market while the sparsely populated area surrounding Featherston forms part of a separate southern Wairarapa labour market.

- Considerable difference existed between labour market catchments and territorial local authorities. Usually this involved a local authority area being comprised of multiple labour markets but discordance also existed, including the labour market catchments of all 15 cities.

\section{Catchment changes 1991-2001}

Around a third of the labour markets identified with 1991 data remained unchanged in 2001. The most frequent change (59 cases) involved the merger of an entire 1991 catchment into another pre-exising catchment. Given the small populations of many catchments, there is sensitivity to small changes in self-containment. On the other hand, there are only 15 areas that are redistributed across two or more catchments. This underscores the overall stability of market boundaries, especially given a possibility that some of the change results from data quality rather than actual behaviour.
Merger of labour market areas is partly a result of urban employment growth and decentralisation into neighbouring centres. Around Auckland, for example, three labour markets (Pukekohe, Waiheke Island and Waiuku) have become absorbed into the two dominant areas of Central and Southern Auckland. The net change in the number of areas is reduced by the emergence of Great Barrier Island as a separate labour market. At the same time, immediately to the north of Central Auckland, the Warkworth labour market has expanded through absorbing part of the former Central Auckland labour market and parts of its other neighbouring market.

The Hamilton and south Waikato region has seen a loss of 12 labour markets and concentration in a significantly enlarged Hamilton catchment and two new areas (South Waikato and Waitomo) formerly comprising six separate travel to work areas. In contrast, the Wellington catchment has experienced little change although it has absorbed the formerly separate Otaki labour market. The previously extensive Christchurch labour market has expended through enveloping parts of four areas (including Hokitika and Wanaka) that survive with changed boundaries. Palmerston North now covers territory formerly divided into three relatively selfcontained markets. Within Otago and Southland, adjustments involving expansion of the Dunedin and Invercargill labour markets have contributed to a loss of two separate catchments.

Other changes arise in the case of provincial centres emerging has more important employment centres for a surrounding rural areas. Thus Masterton and Stratford have each absorbed two smaller catchments.

\section{Sub group local labour markets}

Accessibility to jobs is not just a function of workplace location and residence. The nature of the skills and experience of each person and their relationship to the distribution of corresponding job opportunities is also a major factor. The cost of travel in relation to employment payoff will also vary in relation to wage rates and hours worked, affecting the area over which an individual will seek work.

One approach to uncovering these differences within the population would be to run the algorithm for different subsets of the population and compare the results. Another approach is to estimate and compare the level of self-containtment (effectively the goodness of fit) of each local labour market catchment for each labour market sub group of interest. The former approach would require much more disaggregated data than is currently available from the Census under the confidentiality control procedures in place. It would also require refining model parameters for each category. In contrast, the estimation of sub group self-containment is relatively straightforward. 
The approach adopted here is to estimate residential self containment values for a range of combinations of employee attributes. Letting $T_{i j}$ denote the number of commuting trips from area $i$ to area $j$, this is defined as:

Residential (demand side) self-containment of area $i$ $=\frac{T_{i i}}{\sum_{j=1}^{n} T_{j i}}$.

Once again the analysis presented here makes use of the 1991 area unit based local labour market catchments. Interpretation of the apparent variation in residential selfcontainment needs to note that some attributes are associated with location in the continuum from main urban to rural areas. Labour market catchments are typically larger and less self-contained for main urban than rural areas. This means that some observations may reflect an association with settlement, tune .Higher levels. of self containment generally will be associated with shorter commuting distances but this is not necessarily always the case.

\section{Gender}

A different pattern of commuting for female and male workers may be expected given differences in the participation in household responsiblities and occupation profile. In practice, giving equal weight to each labour market area shows minimal variation in catchment selfcontainment levels between females and males (Table 4.2). There is a slightly higher level of self-containment for females and more variation in the self-containment levels for females than males. This difference suggests less geographical mobility among females but that overall the labour market areas do not contain a substantial gender bias. The pattern differs in the case of the largest urban labour market (Central Auckland) where the residential self containment level varies from 0.81 for males to 0.89 for females. In contrast, the next three largest labour markets (Southern Auckland, Wellington and Christchurch) have less gender variation than the country as a whole.

Table 2 Residential self-containment of 2001 labour markets by gender

\begin{tabular}{|lccc|}
\hline & Male & Female & Total \\
\hline $\begin{array}{l}\text { Residential self } \\
\text { containment }\end{array}$ & 0.882 & 0.906 & 0.894 \\
$\begin{array}{l}\text { Standard deviation of } \\
\text { self containment levels } \\
\text { Number employed }\end{array}$ & 0.093 & 0.095 & 0.091 \\
\hline
\end{tabular}

\section{Occupation}

A preliminary assessment of the variation in selfcontainment by occupation was conducted using at the two digit level of the NZSCO90 which distinguishes 23 occupations. Overall a high level of selfcontainment is maintained for all occupational groups with variations readily explainable by the nature of work. The lowest level of self-containment is found for drivers and mobile machinery operators (0.84) followed by industrial plant operators $(0.85)$. The highest level of self-containment exists among marketorientated agricultural and fishery workers $(0.93)$ and salespersons (0.91).

\section{Ethnicity}

Overall those of New Zealand European ethnic origin are more self contained than other ethnic groups (Table 3). Mäori have a lower level of self-containment mainly as a consequence of reduced male selfcontainment. Smaller ethnic populations exhibit the lowest levels of self-containment.

\section{Income}

Those in the highest and lowest personal income pentiles have lower self containment than those in middle income groups (Table 4). In the case of low income workers, the reduced self-containment is most evident among males. 
Table 3 Residential self-containment of 2001 labour markets by ethnicity and gender

\begin{tabular}{|lcccccc|}
\hline & \multicolumn{2}{c}{$\begin{array}{c}\text { Residential self } \\
\text { containment }\end{array}$} & \multicolumn{2}{c|}{$\begin{array}{c}\text { Standard deviation of } \\
\text { self containment levels }\end{array}$} & \multicolumn{2}{c|}{ Number employed } \\
& Male & Female & Male & Female & Male & Female \\
\hline NZ European Only & 0.891 & 0.913 & 0.092 & 0.094 & 538,476 & 512,979 \\
NZ Mäori & 0.859 & 0.893 & 0.100 & 0.099 & 65,883 & 67,095 \\
Other European & 0.867 & 0.901 & 0.113 & 0.105 & 36,876 & 35,496 \\
Samoan & 0.865 & 0.873 & 0.095 & 0.101 & 13,362 & 13,215 \\
Chinese & 0.835 & 0.857 & 0.133 & 0.135 & 12,891 & 12,501 \\
Indian & 0.819 & 0.851 & 0.116 & 0.115 & 11,862 & 9,825 \\
Cook Island Mäori & 0.856 & 0.866 & 0.127 & 0.123 & 5,124 & 4,962 \\
\hline
\end{tabular}

Table 4 Residential self-containment of 2001 labour markets by income and gender

\begin{tabular}{|c|c|c|c|c|c|c|}
\hline \multirow[b]{2}{*}{$\begin{array}{l}\text { Income group pentile } \\
\text { (5=highest) }\end{array}$} & \multicolumn{2}{|c|}{$\begin{array}{l}\text { Residential self } \\
\text { containment }\end{array}$} & \multicolumn{2}{|c|}{$\begin{array}{c}\text { Standard deviation of } \\
\text { self containment levels }\end{array}$} & \multicolumn{2}{|c|}{$\begin{array}{l}\text { Number employed } \\
\text { among all income } \\
\text { earners }\end{array}$} \\
\hline & Male & Female & Male & Female & Male & Female \\
\hline 1 & 0.888 & 0.914 & 0.085 & 0.080 & 17,592 & 19,470 \\
\hline 2 & 0.922 & 0.934 & 0.056 & 0.062 & 43,023 & 75,249 \\
\hline 3 & 0.909 & 0.928 & 0.067 & 0.074 & 49,320 & 107,667 \\
\hline 4 & 0.901 & 0.917 & 0.075 & 0.090 & 115,869 & 162,978 \\
\hline 5 & 0.885 & 0.894 & 0.093 & 0.115 & 203,529 & 177,576 \\
\hline
\end{tabular}

\section{Hours worked}

Individuals working less than full time or excessive hours in their main job are generally more self-contained than those with 'normal' full time hours of work. Thus for both female and male work of less than 20 hours per work the self containment levels are over 0.9 . The aggregate self-containment level drops to 0.86 among those working 45-49 hours per work.

\section{Age}

Levels of self-containment by age group largely follow expected patterns. The youngest working people (15-17) show high levels of self-containment (0.93) with older age groups showing more mobility up to the 50 to 54 year cohort, after which self-containment increases to 0.95 for those aged 75-79. Self-containment is lowest for persons aged 25-29 (0.87). An unusual finding is the comparatively low self-containment of working persons of over 85 years $(0.87)$ but this group numbers 627 in total and probably relates to particular forms of employment.

\section{Conclusion}

This paper has summarised how the aggregate working population has been apportioned to relatively self- contained labour market areas. The general conclusion is that the algorithm modified from the method developed by Coombes, and first applied in New Zealand with 1991 Census data by Newell and Papps (2001), provides a robust basis for delineating local labour markets. This is judged by the overall stability in labour market boundaries and the consistently high levels of aggregate self-containment for labour market sub groups. That said, four qualifications to the success of the method are acknowledged that provide opportunities to extend the analysis so far completed.

The 2001 update has been constructed from area unit data. The original intention of utilising mesh block data was abandoned because of the high proportion of Census returns that do not have a workplace address coded to a mesh block. Consideration needs to be given to devising appropriate methods for estimating missing addresses so as to provide a set of catchments with a higher level of geographical resolution than so far produced.

Use of the self-containment level to determine the retention of catchment areas among different labour market groups provides a partial assessment. An alternative method is to generate specific sub group catchments, using scaled down size requirements. This approach would provide more insight into the daily labour markets of individual groups than the aggregate self-containment statistics. Particularly in the case of the large urban labour markets there is justification for exploring the labour market foci for each catchment. 
Even using the existing boundaries there is considerable scope to examine changes in labour market areas from 1991 to 2001. A preliminary comparison, as presented here, suggests the contribution of urbanisation processes but there are also some rural areas that have experienced catchment changes. The sources of boundary changes and role of different sub groups in promoting change should form part of the larger evaluation of the usefulness of travel to work areas as a basis for monitoring local employment change.

The apparent increase of long distance commuting was highlighted as potentially an aspect of modern labour markets that challenge the existence of localised catchment areas. The present study has removed selected long distance commutes that seemed improbable or potentially temporary. Further examination of these moves is possible to determine whether they are associated with particular occupations that may permit the geographical flexibility implied. If a real increase in long distance commuting is sustained, there is a need to consider how this affects the use of catchments that essentially envisage commuting as a daily occurrence.

\section{Acknowledgements}

The project arose from financial support jointly awarded to the New Zealand Treasury and Department of Labour from the Departmental Contestable Research Pool, Ministry of Research Science and Technology. The authors are solely responsible for the use of the data and its interpretation in this paper.

\section{References}

Ball, R. (1980) The use and definition of travel to work areas in Great Britain: some problems. Regional Studies, 14, 125-139.

Choy, W.K., Maré, D. and Mawson, P. (2002) Modelling regional labour market adjustment in New Zealand, Treasury Working Paper 02/01. New Zealand Treasury: Wellington.

Coombes, M. G. (2001) Geographical information systems: a challenge for statistical agencies. Paper prepared for submission to Research in Official Statistics.

Coombes, M. G. and Openshaw, S. (1982) The use and definition of travel to work areas in Great Britain: some comments. Regional Studies, 16, 141-149.

Coombes, M. G., Green, A. and Openshaw, S. (1986) An efficient algorithm to generate official statistical reporting areas: the case of the 1984 travel to work areas revision in Britain. Journal of the Operational Research Society, 37, 943-953.

Goodman, J.F.B. (1970) The definition and analysis of lcoal labour markets: some empirical problems. British Journal of Industrial Relations, 8, 179196.

Green, A. (1994) The role of migration in labour market adjustment: the British experience in the $1980 \mathrm{~s}$. Environment and Planning A, 26, 1563-1577.

Newell, J. and Papps, K. (2001) Identifying functional labour market areas in New Zealand: a reconnaissance study using travel-to-work data. Occasional Paper 2001/6, Department of Labour: Wellington. 